\title{
IODINE STATUS NOT ASSOCIATED WITH COGNITIVE FUNCTIONING IN OLDER AUSTRALIANS
}

\author{
L. Buchanan ${ }^{1}$, K.E. Charlton'2, S. Roodenrys ${ }^{3}$, D. Cocuz $z^{3}$, T. Pendergast ${ }^{3}$, G. Ma ${ }^{4}$
}

\begin{abstract}
Objective: This study aims to investigate whether iodine status is associated with cognitive functioning and mood state in a sample of healthy older Australians. Design: Cross-sectional study. Setting: Illawarra region of New South Wales, Australia. Participants: Eighty-four men and women (25 males; 59 females) aged 60-95 years with normal cognitive function. Measurements: Three repeated fasting urine samples were collected a week apart to assess median urinary iodine concentration for the group. Usual dietary iodine intake was measured using an iodine-specific food frequency questionnaire and three repeated 24-hour dietary recalls while nutritional status was assessed using the Mini Nutritional Assessment (MNA). Cognitive function was assessed by the CogState battery of tests and the Rey Auditory Verbal Learning Task (RAVLT) and mood state determined by the Geriatric Depression Scale (GDS). Associations between iodine status and cognitive tests were assessed by Wilcoxon signedrank, Pearson, and Spearman rank correlation tests. Results: Median urinary iodine concentration (MUIC) indicated mild iodine deficiency $(71 \mu \mathrm{g} / \mathrm{L} ; \mathrm{IQR}=55-102 \mu \mathrm{g} / \mathrm{L})$. Iodine status was not significantly associated with any domains of cognitive function. Memory was negatively correlated with mood state $(\mathrm{r}=-0.375 ; \mathrm{P}<0.05)$ and positively associated with nutritional status $(\mathrm{r}=$ 0.235; $\mathrm{P}<0.05)$. Conclusion: Iodine status is not associated with cognitive functioning in a sample of older people with mild iodine deficiency. It remains to be seen whether correction of more severe iodine deficiency in this age group would have a beneficial impact on domains of attention, visuospatial processing, and executive processing.
\end{abstract}

Key words: Iodine, dietary intake, cognition, mood state, older adults.

\section{Introduction}

Iodine plays a key role in maintaining the normal function of the thyroid, and is an essential component in the molecular structure of thyroid hormones, thyroxine (T4) and triiodothyronine (T3) (1). Deficiency in thyroid hormone production leads to a generalised reduction of regional cerebral blood flow and brain activity, which in turn may adversely affect cognitive functioning (2). Various studies have demonstrated poor thyroid functioning to be associated with depressive symptoms, as well as cognitive decline in adults (3-6). Despite numerous studies showing associations between iodine repletion and improved cognitive performance in young children (2, 7-9), evidence of this type is not available for older people. There is some evidence that malnutrition impairs cognitive abilities in older persons (10-13)

1. School of Health and Society, Faculty of Social Sciences, University of Wollongong, NSW, Australia; 2. School of Medicine, Faculty of Science, Medicine and Health, University of Wollongong, NSW, Australia; 3. School of Psychology, Faculty of Social Sciences, University of Wollongong, NSW, Australia; 4; Institute of Clinical Pathology and Medical Research (ICPMR), Westmead Hospital, Sydney, NSW, Australia.

Corresponding Author: Karen E. Charlton, School of Medicine, Faculty of Science. Medicine and Health, University of Wollongong, Wollongong, NSW 2522, Tel: +61 24221 4754; Fax: +61 24221 3486; Email: karenc@uow.edu.au but this is not related to a suboptimal iodine status, specifically. Given that impaired cognitive abilities and mood state disorders are important determinants of independence in older adults (3), further elucidation of dietary factors that may be targeted for intervention is of particular importance.

Iodine deficiency re-emerged among Australian school-aged children and pregnant women in the 2000s (14-19). In an attempt to address this issue, mandatory fortification of iodised salt in bread was introduced by Food Standards Australia and New Zealand (FSANZ) in October 2009 (20). Evaluation of the impact of this public health strategy has focused on pregnant women and schoolchildren (21-24), but the most recent national health survey data on nutritional biomarkers suggests that the mild iodine deficiency has been corrected in older adults.

Over $14 \%$ of the Australian population is aged 60 years and older (25). A decline in cognitive functioning with age seems inevitable. Although it is difficult to clearly distinguish pathological effects of aging on cognitive function from non-pathological, it is clear that many factors may contribute to cognitive decline, including dietary factors. It is also clear that cognitive decline has a major impact on everyday functioning and is a 
major cause of older adults entering care (26). Given the evidence described above and the finding that treatment of hypothyroidism has been shown to improve cognitive function (27), it is possible that dietary iodine may be associated with the current level of cognitive function in older adults. The aim of this study was to assess the association between iodine status and domains of cognitive function, mood and memory in a sample of older Australians prior to introduction of a mandatory iodine fortification programme.

\section{Methods}

\section{Subjects}

One hundred and ten English-speaking men and women aged 60 - 95 years living in aged care facilities (independent retirement villages, assisted living, and

Table 1

Task information of the Cogstate battery of tests and cognitive function assessed

\begin{tabular}{|c|c|c|c|}
\hline Task name & $\begin{array}{l}\text { Task code (variable } \\
\text { codes }^{*} \text { ) }\end{array}$ & Cognitive function tested & Description \\
\hline Detection Task & DET (lmn, lsd, acc) & $\begin{array}{l}\text { Processing and psychomotor } \\
\text { function }\end{array}$ & $\begin{array}{l}\text { Subjects are asked "has the card turned } \\
\text { over"? A playing card is presented face } \\
\text { down in the centre of the screen; the subject } \\
\text { is required to press the "Yes" key as soon as } \\
\text { the card flips over. }\end{array}$ \\
\hline Groton Maze Learning Task & GML (ter) & $\begin{array}{l}\text { Spatial problem solving and } \\
\text { executive function }\end{array}$ & $\begin{array}{l}\text { This contains } 5 \text { learning rounds. The task } \\
\text { requires the subjects to navigate a } 28 \text { steps } \\
\text { pathway through a } 10 \times 10 \text { grid of tiles on } \\
\text { the computer screen. Subjects learn the } \\
\text { pathway through trial and error feedback. } \\
\text { Performance is measured by the number of } \\
\text { errors made in learning the pathway. Each } \\
\text { of the } 5 \text { learning trials are: } \\
\text { GML1 First round of GML } \\
\text { GML2 Second round of GML } \\
\text { GML3 Third round of GML } \\
\text { GML4 Fourth round of GML } \\
\text { GML5 Fifth round of GML }\end{array}$ \\
\hline
\end{tabular}

One Card Learning Task OCL (lmn, lsd, acc) Learning and memory

One Back Task

ONB (lmn, lsd, acc)

Two Back Tasks

TWOB (lmn, lsd, acc)

Set Shifting Task
Attention and working memory-simple

Attention and working memory-complex

Executive function
The subjects are asked "have you seen this card before in this task". A playing card is presented in the centre of the screen and the subject must decide if they have seen the card before and respond by pressing the "Yes" or the "No" key. Incorrect responses are followed by an error sound.

A playing card is presented face up in the centre of the screen and the subject has to decide if the card is identical to the one immediate before it and press either the yes or the no key.

The subject is asked if the playing card in the centre of the screen is the same as that shown two cards ago. They then press either the "Yes of the "No" key.

Subjects are presented with a playing card on the screen and are asked to determine if it is a target or "correct" card (based of a colour or a number). The subjects begin by guessing and over a number of trials learn that a specific dimension (colour or number) is "correct". After making their way through a set of cards the "correct" dimension changes. The change may to the opposing example within the same dimension (e.g. from red to black), or to a different dimension altogether (e.g. from a number to a colour).

* Description of variable codes listed in Table 2. (CogState Ltd., 2009a) 
low care facilities) in the Illawarra region of New South Wales, volunteered to participate in the study. Twentysix people were excluded because of one or more of the following exclusion criteria: a) diagnosed dementia and/ or Alzheimer's disease, b) cognitive decline as indicated by a Mini-Mental State Examination (MMSE) score of $<=23(28), c)$ a previous stroke, d) current use of thyroxine or any other medications that may affect memory, 5) uncontrolled hypertension (blood pressure (BP) $\geq 160 / 95$ $\mathrm{mm} \mathrm{Hg}$ ), or e) uncontrolled diabetes (blood glucose (BG) $\geq 7.8 \mathrm{mmol} / \mathrm{l})$.

\section{Measures}

\section{Assessment of Iodine Status and Nutritional Status}

Participants were visited in their homes weekly over a three week period for collection of spot urine samples, and to administer the dietary assessments and cognitive performance tests. First voided urine samples were collected and stored at $-80^{\circ} \mathrm{C}$ until all samples could be batch-analysed by the accredited laboratory of the Institute of Clinical Pathology and Medical Research (ICPMR), Westmead Hospital (Sydney, NSW, Australia). Urinary iodine concentration (UIC) was analysed using an adaptation of the Sandell-Kolthoff method using the microplate method (29) with ammonium persulphate digestion and microplate reading. Sensitivity of the urinary iodine assay is $5 \mu \mathrm{g} / \mathrm{L}$. At $46 \mu \mathrm{g} / \mathrm{L}( \pm 7.72$ (i.e. 2SD)) the coefficient of variation (CV) is $16.7 \%$, at 153 ( \pm $8.9) \mu \mathrm{g} / \mathrm{L}$ the $\mathrm{CV}$ is $5.8 \%$, while at $347( \pm 30)$ the $\mathrm{CV}$ is $8.65 \%$

Dietary iodine intake was measured by a validated iodine-specific Food Frequency Questionnaire (FFQ) (30) and three repeated 24 -hr dietary recalls $(3 \times 24 h r$ DR). Nutritional status of subjects was assessed using the

validated 18-item Mini Nutritional Assessment (MNA) and scored according to the categories of $\geq 24,17-23.9$, and $<17$, for classification of well nourished, at-risk of malnutrition, or malnutrition, respectively (31).

\section{Cognition, Memory and Mood State Assessments}

Tasks from the CogState battery of tests (32) were presented on a laptop computer and tests were delivered in the format of a set of digital playing cards. This method has been shown to be readily understandable and accepted by older participants (33). Participants were given 45-50 mins to complete the tests which examined their domains of attention, visuospatial processing, and executive processing, as listed in Table 1.

Memory was assessed using the Rey Auditory Verbal Learning Task (RAVLT) (34), which requires participants to remember a list of semantically unrelated words (see Table 2 for details of the measures from this task). The 15-item Geriatric Depression Scale (GDS) (35) was administered to assess participant's mood state (score $=0$ -15). A higher score indicates greater levels of depressive symptomatology and a cut-off of 5 indicates some form of depression (35-36).

\section{Data analyses}

The mean of the three urinary iodine concentrations (UIC) of each participant was used to assess group median UIC, according to the UIC reference values of the World Health Organization and the International Committee on the Control of Iodine Deficiency Disorders (ICCIDD) [iodine-replete: UIC $\geq 100 \mu \mathrm{g} / \mathrm{L}$; iodinedeplete: UIC $\leq 100 \mu \mathrm{g} / \mathrm{L}]($ WHO/UNICEF/ICCIDD 1994). UIC was also expressed as a ratio of UIC:creatinine $(\mu \mathrm{g} / \mathrm{g})(37)$.

Table 2

Cognitive measures in the CogState battery of tests

\begin{tabular}{|c|c|c|c|}
\hline Variable code & Unit of Measurement & Relevant to & Description \\
\hline $\operatorname{lmn}$ & Log10 milliseconds & All tasks except GML & $\begin{array}{l}\text { Speed of performance; mean of the } \\
\text { log10 transformed reaction times } \\
\text { for correct responses } \\
\text { Lower score = better performance }\end{array}$ \\
\hline Lsd & Log10 milliseconds & All tasks except GML & $\begin{array}{l}\text { Consistency of performance; } \\
\text { standard deviation of the log } 10 \\
\text { transformed reaction times for } \\
\text { correct responses } \\
\text { Higher score = better performance }\end{array}$ \\
\hline Acc & Arcsine proportion & All tasks except GML & $\begin{array}{l}\text { Accuracy of performance; arcsine } \\
\text { transformation of the proportion } \\
\text { of correct responses } \\
\text { Higher score = better performance }\end{array}$ \\
\hline Ter & Count & GML & $\begin{array}{l}\text { Total number of errors } \\
\text { Lower score = better performance }\end{array}$ \\
\hline
\end{tabular}

(CogState Ltd., 2009b) 


\section{Statistical analysis}

Statistical analyses were performed using the Statistical Package for Social Sciences (V15.0.0 SPSS Inc., Chicago IL, USA) (38). Tests for normality of the data were performed using the Kolmogorov-Smirnov test. Pearson or Spearman rank correlation coefficients were used to determine the relationship of the methods to measure iodine status, and the association between iodine status, cognitive and memory functioning, and mood state. Statistical significance was set at $\mathrm{p}<0.05$.

\section{Results}

The characteristics of the 84 participants ( 25 men; 59 women) are shown in Table 3. Median UIC indicated mild iodine deficiency $(71 \mu \mathrm{g} / \mathrm{L} ; \mathrm{IQR}=55-102 \mu \mathrm{g} / \mathrm{L})$. When calculated as a ratio of UIC: creatinine, the mean value for 3-day spot urine samples was $123.9 \pm 55.3$ $\mu \mathrm{g} / \mathrm{g}$. Dietary iodine intake of participants in this study, measured by both the iodine-specific FFQ and the average of the three 24-hr dietary recalls were higher than those reported in the 22nd Australian Total Diet Study; median dietary iodine intake for men was $106 \mathrm{ug} /$ day (FFQ) and $117 \mathrm{ug} /$ day (24-hr dietary recall) while for women was $107 \mathrm{ug} /$ day (FFQ) and $105 \mathrm{ug} /$ day (24-hr dietary recall). Details of participants' dietary intake are reported elsewhere (Tan et al. 2013). All except four subjects $(5 \%)$ were classified as being well nourished, according to the MNA classification.

\section{Association between Iodine status, cognitive function, mood state and memory}

Only four variables in the CogState battery of tests were significantly associated with either urinary iodine status or dietary iodine intake, but some were unexpectedly inversely correlated. These included: accuracy of performance in the Set Shifting Task (SETacc) and UIC $(r=-0.253 ; p<0.05)$; the number of errors made in the Groton Maze Learning Task (GML) $((\mathrm{r}=$ $0.343 ; \mathrm{p}<0.05)$ and dietary iodine intake $(\mathrm{FFQ})$; speed of performance in the Detection Task and dietary iodine intake ( $3 \times 24-h r$ DR) $(r=-0.231 ; p<0.05)$; and the accuracy of performance in the Set Shifting Task and dietary iodine intake $(3 \times 24-h r D R)(r=-0.261 ; p<0.05)$. Analyses were also performed using iodine expressed per unit creatinine and iodine/creatinine/body weight to account for renal function and body weight of the subjects. However, findings did not change (data not shown). None of the tests in the RAVLT series were significantly correlated with UIC. The RAVLT False Alarm (FA - i.e. number of words indicated during a recognition task as being on the list which, in fact, were not) was inversely associated $(\mathrm{r}=-0.238 ; \mathrm{p}<0.05)$ with reported dietary iodine intake (FFQ).

Mood state was not related to either UIC nor dietary iodine intake.

\section{Association between Nutritional status and Cognitive and Memory Functions}

A higher MNA score (i.e. better nutritional status) was inversely associated $(\mathrm{r}=-0.258, \mathrm{p}<0.05)$ with number

Table 3

Tests information of the Rey Auditory-Verbal Learning Test (RAVLT) and the cognitive function assessed

\begin{tabular}{|c|c|c|c|}
\hline Test name & Test code & Cognitive function measure & Description \\
\hline $\begin{array}{l}\text { Learning trials I-V } \\
\text {-Learning trials I }\end{array}$ & $\begin{array}{l}\text { Ravlt I-V } \\
\text {-Ravlt I }\end{array}$ & $\begin{array}{l}\text { Attention and memory } \\
\text {-immediate memory }\end{array}$ & $\begin{array}{l}\text { The words on List A are read } \\
\text { aloud and the subject is asked to } \\
\text { recall as many words as he/ she } \\
\text { can in any order. }\end{array}$ \\
\hline Interference trial & Ravlt Int & $\begin{array}{l}\text { Proactive interference- the degree } \\
\text { in which old learning can interfere } \\
\text { with new learning. }\end{array}$ & $\begin{array}{l}\text { A new list is read aloud (List B) } \\
\text { and free recall was requested. }\end{array}$ \\
\hline Trial VI & Ravlt VI & $\begin{array}{l}\text { Retroactive interference- the situa- } \\
\text { tion where new learning interferes } \\
\text { with the recall of old information. }\end{array}$ & $\begin{array}{l}\text { The subject is asked to recall the } \\
\text { words they learnt from List A. }\end{array}$ \\
\hline Hits & Ravlt Hit & Memory & $\begin{array}{l}\text { From the recognition test. The } \\
\text { number of words from List A } \\
\text { recognised (out of 15) }\end{array}$ \\
\hline Missess & Ravlt Miss & Memory & $\begin{array}{l}\text { From the recognition test. The } \\
\text { number of words on the list that } \\
\text { were not recognised. }\end{array}$ \\
\hline False Alarms & Ravlt FA & Memory & $\begin{array}{l}\text { From the recognition test. The nu- } \\
\text { mber of words indicated as being } \\
\text { on the list that were, in fact, not. }\end{array}$ \\
\hline
\end{tabular}


of errors made by the subjects in the GML task, but no association with the other tasks were found. MNA score was significantly correlated with performance in three measures in the RAVLT task, namely Ravlt (I-V) $(\mathrm{r}=0.235, \mathrm{p}<0.05)$ which measures performance across the 5 learning trials; Ravlt Int $(\mathrm{r}=0.349, \mathrm{p}<0.05)$ which measures performance in learning a new list of words; and Ravlt FA ( $\mathrm{r}=-0.246, \mathrm{p}<0.05)$. After removing an outlier on the GDS measure, MNA did not correlate significantly with GDS score.

\section{Table 4}

Demographic and clinical characteristics of study subjects $(\mathrm{n}=84)$

\begin{tabular}{|c|c|}
\hline Characteristics & Subjects $(\mathrm{n}=84)(\%)$ \\
\hline \multicolumn{2}{|l|}{$\operatorname{Sex}(\%)$} \\
\hline Males & $25(30 \%)$ \\
\hline Females & $59(70 \%)$ \\
\hline Age (years) & $74 \pm 8^{\mathrm{a}}$ \\
\hline \multicolumn{2}{|l|}{$\mathrm{BMI}^{\mathrm{b}}$} \\
\hline Mean & $28.4 \pm 4.7^{\mathrm{a}}$ \\
\hline Underweight $\left(\leq 18.5 \mathrm{~kg} / \mathrm{m}^{2}\right)$ & $0(0 \%)$ \\
\hline Normal Weight $\left(18.5-24.9 \mathrm{~kg} / \mathrm{m}^{2}\right)$ & $16(19 \%)$ \\
\hline Overweight $\left(\geq 24.9 \mathrm{~kg} / \mathrm{m}^{2}\right)$ & $45(54 \%)$ \\
\hline Obese $\geq\left(30 \mathrm{~kg} / \mathrm{m}^{2}\right)$ & $23(27 \%)$ \\
\hline \multicolumn{2}{|l|}{ MNA score } \\
\hline Mean & $27.2 \pm 3.6^{a}$ \\
\hline Malnourished (<17 points) & $0(0 \%)$ \\
\hline At risk of Malnutrition (17 - 23.5 points) & $4(5 \%)$ \\
\hline Well-nourished ( $\geq 24$ points) & $78(93 \%)$ \\
\hline Unknown & $2(2 \%)$ \\
\hline \multicolumn{2}{|l|}{ Barthel Index ${ }^{17}$} \\
\hline $\begin{array}{l}\text { Able to independently perform activities of } \\
\text { daily living ( }>50 \text { points) }\end{array}$ & $84(100 \%)$ \\
\hline \multicolumn{2}{|l|}{ MMSE score ${ }^{18}$} \\
\hline 0 to 23 & $0(0 \%)$ \\
\hline $24-30$ & $83(99 \%)$ \\
\hline Unknown & $1(1 \%)$ \\
\hline \multicolumn{2}{|l|}{ Education level } \\
\hline$\leq$ Year 12 & $39(47 \%)$ \\
\hline$>$ Year 12 & $44(52 \%)$ \\
\hline Unknown & $1(1 \%)$ \\
\hline
\end{tabular}

a. Mean \pm standard deviation; $\mathrm{b}$. Calculated as $\mathrm{kg} / \mathrm{m}^{2}$

\section{Association between Mood state and Cognitive and Memory Functions}

One participant was classified as mildly depressed, while the rest scored normally on the Geriatric
Depression scale (Yesavage et al., 1983). None of the tasks within the CogState battery of tests were associated with the depression score. GDS was significantly inversely correlated with the tests within the RAVLT $(r=-0.226$ to -0.375) except for Ravlt Miss and Ravlt FA. The lower the GDS score (less depressed), the better the subjects performed in the RAVLT (RAVLT I-V $\mathrm{r}=-0.375$; RAVLT Int $\mathrm{r}=$-1.239; RAVLT VI $\mathrm{r}=-.0 .380$; RAVLT Hit $\mathrm{r}=-0.226$ ).

\section{Discussion}

Contrary to our study hypothesis, we found no evidence that higher iodine levels, assessed using repeated urinary or dietary measures, were associated with better cognitive function, memory performance or mood state in a sample of healthy, independently-living older people. Similarly, performance on tests across a range of cognitive domains was not associated with a composite and validated measure of nutritional status. However, nutritional status and level of depression appear to be independently related to memory function, as indexed by performance on the various measures of the RAVLT task.

This sample of otherwise healthy older Australians had mild iodine deficiency (median UIC $=71 \mu \mathrm{g} / \mathrm{L}$ ), as had been reported in groups of children and pregnant women in the country $(14-16,37-38)$ prior to introduction of the mandatory iodine fortification program in Australia in 2009 (20). A lack of published literature on the impact of suboptimal iodine intakes on cognitive function and mood state in older people with no clinical cognitive impairment limits interpretation of our findings. A randomized, controlled trial (41) which investigated the effects of iodized poppy seed oil on cognitive and motor function in school-aged children with normal thyroid function reported no benefits after four months of intervention, and suggested that low urinary iodine biomarkers, in the presence of normal thyroid function does not affect cognitive function.

Several possibilities may explain the lack of association between iodine status and cognitive functioning among elderly people. Iodine-related cognitive deficits may only occur in individuals with hypothyroidism, a group that we attempted to exclude from the present study. Hashimoto et al. (42) found that congenital hypothyroidism caused cognitive and memory dysfunction in mice. Experimental hypothyroidism in their study resulted in impaired learning in developing mice. Similarly, another study on iodinedeficient or hypothyroid rats suggested that iodine deficiency and hypothyroidism during critical periods of brain development resulted in abnormalities in the hippocampus, an area of the brain which is known to be important for cognitive and memory performance (43). An intervention trial conducted by Zimmermann et al. (2) demonstrated that iodine treatment for 24 weeks improved iodine status and cognition of children with 
Table 5

Pearson correlations of the tasks within the CogState battery of tests with urinary iodine concentration and dietary iodine intakes from the iodine-specific food frequency questionnaire (ISFFQ) and the 24-hr dietary recall (24-hr DR)

\begin{tabular}{|c|c|c|c|}
\hline CogState task & Urinary iodine concentration & Dietary iodine intake from ISFFQ & $\begin{array}{l}\text { Dietary iodine intake from } 24-\mathrm{hr} \\
\text { DR }\end{array}$ \\
\hline \multicolumn{4}{|c|}{ Detection Task (DET) } \\
\hline$-\operatorname{lmn}$ & -0.128 & 0.062 & $-0.231^{*}$ \\
\hline -lsd & -0.152 & -0.072 & -0.083 \\
\hline -acc & 0.091 & 0.012 & -0.079 \\
\hline \multicolumn{4}{|c|}{$\begin{array}{l}\text { Groton Maze Learning Task } \\
\text { (GML) }\end{array}$} \\
\hline -ter1 & -0.035 & 0.000 & 0.048 \\
\hline -ter2 & -0.031 & 0.155 & 0.154 \\
\hline -ter3 & -0.022 & 0.094 & 0.121 \\
\hline -ter4 & 0.011 & 0.082 & 0.083 \\
\hline -ter5 & -0.133 & $0.343^{*}$ & 0.025 \\
\hline \multicolumn{4}{|c|}{ One Card Learning Task (OCL) } \\
\hline$-\operatorname{lmn}$ & -0.103 & 0.130 & -0.077 \\
\hline -lsd & 0.006 & -0.122 & -0.106 \\
\hline -acc & 0.036 & -0.160 & -0.195 \\
\hline \multicolumn{4}{|c|}{ One Back Task (ONB) } \\
\hline$-\operatorname{lmn}$ & -0.105 & 0.010 & 0.005 \\
\hline -lsd & -0.069 & -0.152 & 0.133 \\
\hline -acc & 0.084 & 0.069 & -0.095 \\
\hline \multicolumn{4}{|c|}{ Two Back Tasks (TWOB) } \\
\hline$-\operatorname{lmn}$ & -0.160 & 0.049 & 0.004 \\
\hline -lsd & -0.024 & 0.171 & 0.167 \\
\hline -acc & 0.192 & -0.018 & -0.029 \\
\hline \multicolumn{4}{|c|}{ Set Shifting Task (SET) } \\
\hline$-\operatorname{lmn}$ & -0.092 & 0.068 & 0.131 \\
\hline -lsd & 0.073 & -0.067 & -0.123 \\
\hline$-\mathrm{acc}$ & $-0.253^{*}$ & 0.030 & $-0.261^{*}$ \\
\hline
\end{tabular}

$\mathrm{DET}=$ Detection Task; GML=Groton Maze Learning Task; $\mathrm{OCL}=$ One Card Learning Task; ONB= One Back Task; TWOB= Two Back Tasks; SET= Set Shifting Task; ter $(1,2 \ldots)=$ Total number of errors in GML (round 1,2..); $1 \mathrm{mn}=$ Speed of performance; lsd= Consistency of performance; acc= Accuracy of performance; * Correlation is significant at the 0.05 level (2-tailed).

moderate iodine deficiency. Since cognitive deficits may only occur in iodine-deficient individuals with hypothyroidism, the assessment of thyroid hormones may have provided more insight into the iodinecognition relationship.

Another explanation may be that iodine deficiency may affect fetal brain development but not impact on functioning in an adult's brain. Indeed, experimental studies in the rat model have shown that maternal (46) and fetal iodine deficiency (45) results in early developmental defects in the hippocampus of the brain. The crucial role of thyroid hormones on human fetal brain development is well established (46-47). However, there are limited studies on the impact of iodine deficiency on cognitive functioning of adults. One study that investigated the effect of thyroid hormone replacement on cognitive function in adult hypothyroid rats (48) did not demonstrate cognitive benefits after the thyroid hormone treatment, although one small study with humans did find some benefit (27).

The negative correlation between iodine measures and performance on some cognitive task measures is unexpected. The speed of performance in the detection task was faster for participants with higher levels of iodine, as might be expected if iodine is important for cognitive function. However, participants with high iodine consumption made more errors on some tasks. This correlation may be explained by a speed-accuracy 
Table 6

Pearson correlations of the tests within the RAVLT (Rey Verbal Learning Task) with urinary iodine concentration and dietary iodine intakes from the iodine-specific Food Frequency Questionnaire and the 24-hr Dietary Recall

\begin{tabular}{|c|c|c|c|}
\hline RAVLT & Urinary iodine (ug/L) & Dietary iodine intake from ISFFQ & $\begin{array}{l}\text { Dietary iodine intake from 24-hr } \\
\text { DR }\end{array}$ \\
\hline Ravlt I-V & -0.009 & 0.131 & 0.038 \\
\hline Ravlt Int & -0.007 & 0.030 & 0.036 \\
\hline Ravlt VI & 0.031 & 0.056 & 0.064 \\
\hline Ravlt Hit & -0.028 & 0.020 & 0.112 \\
\hline Ravlt Miss & 0.019 & -0.044 & -0.123 \\
\hline Ravlt FA & -0.057 & $-0.238^{*}$ & -0.016 \\
\hline
\end{tabular}

*Correlation is significant at the 0.05 level (2-tailed).

tradeoff in those tasks, where speed and accuracy were negatively correlated. Those participants with higher iodine intake had a tendency to respond more quickly but less accurately. This may be an effect of iodine on the overall pattern of responding or it may be coincidental and reflect a type I error, given the large number of correlations that were tested.

Memory (verbal learning and recall) and performance on the other cognitive tasks was not associated with the iodine status of our participants. Similarly, a clinical trial by Chandra (55) found that supplementation with vitamins and trace elements did not significantly improve memory in healthy elderly subjects. Supplementation studies that have found significant improvements in memory with multivitamin supplementation included frail elderly participants or those who had already experienced memory difficulties $(53,56)$. Memory deficits associated with thyroid function may only be apparent in individuals with severe iodine deficiency or altered thyroid function.

Memory performance was however associated with nutritional status and mood state. Our findings are consistent with other studies. Feng et al. (57) reported a positive association between better performance on the RAVLT test and a higher Vitamin B-12 intake. Similarly, The NEMO Study Group (58) demonstrated that micronutrient supplementation, though not inclusive of iodine, improved verbal learning and memory in Australian school-aged children. Several cross-sectional studies suggest an association between vitamin B-12 and iron intakes and memory in children (59-60). An inverse association between mood state and memory function in healthy populations has been well documented (61).

Limitations to the study include potential bias in the measurement of cognition. The CogState battery of tests has been shown to have high reliability and sensitivity when used to assess cognitive performance of older people, however many of these validation studies have involved older adults with some form of cognitive impairment, for instance, those at risk of having dementia or those with HIV- associated neurocognitive impairment
(49-50). Clinical trials that used a computerized battery of cognitive tests have failed to identify any significant effect of multivitamin supplementation on cognitive performance among healthy elderly (51-53). It may be that the types of tests included in this format are not sufficiently sensitive to assess subtle differences among healthy older individuals. Older adults with low MMSE scores were not eligible for inclusion in the study, which may have resulted in a range and distribution of cognitive function test results that is too narrow to detect significant relationships with iodine status.

\section{Table 7}

Spearman correlations of the tests within the Rey Auditory Verbal Learning Task (RAVLT) with the 15-items Geriatric Depression Scale (GDS)

\begin{tabular}{|c|c|}
\hline RAVLT & GDS \\
\hline Learning Trial I-V (Ravlt I-V) & $-0.375^{* *}$ \\
\hline -Trial I (Ravlt I) & $-0.287^{*}$ \\
\hline Interference Trial (Ravlt Int) & $-0.239^{*}$ \\
\hline Trial VI (Ravlt VI) & $-0.380^{* *}$ \\
\hline Number of words recognised (Ravlt Hit) & $-0.226^{*}$ \\
\hline Number of words Not recognised (Ravlt Miss) & 0.218 \\
\hline $\begin{array}{l}\text { Number of words indicated being on the list, in fact, not } \\
\text { (Ravlt FA) }\end{array}$ & 0.211 \\
\hline \multicolumn{2}{|c|}{$\begin{array}{l}\text { Ravlt }(\mathrm{I}-\mathrm{V})=\text { Sum of learning trials I through } \mathrm{V} \text {, involve the repeated reading } \\
\text { of the test list (List A); Ravlt I= Trial 1, measure of immediate memory; Ravlt } \\
\text { Int= Interference trial in which a new list (List B) is read to the subject; Ravlt } \\
\mathrm{VI}=\text { Trial 6, subject is asked to recall as many words as he/she can from the } \\
\text { List A after the interference trial; Ravlt Hit (Hits)= number of words from List } \\
\text { A recognised; Ravlt Miss (Misses)= number of words on List A that were not } \\
\text { recognised; Ravlt FA (False Alarms)= number of words indicated as being on } \\
\text { the List A that were, in fact, not; }{ }^{* *} \text { Correlation is significant at the } 0.01 \text { level } \\
\text { (2-tailed); }{ }^{*} \text { Correlation is significant at the } 0.05 \text { level (2-tailed). }\end{array}$} \\
\hline
\end{tabular}

The internationally recommended method for assessing population-level adequacy of iodine status was used in the current study, namely median urinary iodine concentrations (MUIC), expressed as $\mu \mathrm{g}$ per litre of urine. Reference values for MUIC have been developed 
for schoolchildren aged 6-12 y, in whom an average urinary excretion volume of 1 litre per day is assumed (62). Age-related impairments in renal function may affect urinary volume output in older people and thereby limit interpretation of the MUIC values. Using laboratory reference cut-offs for urinary creatinine, and assuming a urinary volume of $1.5 \mathrm{~L}$ per day, $44 \%$ of the study subjects had values below the lower range (data not shown). It is therefore possible that spot UIC values may be under-estimating $24 \mathrm{hr}$ excretion in this study population, as has been reported by Kim et al. (37). A review has identified that UIC is a useful biomarker of iodine status, and that an association between UIC and iodine supplemental intake exists. The review goes on to demonstrate that bioavailability of dietary iodine intake is high (63).

A strength of the current study is that it attempted to capture day-to-day variability of iodine consumption by the collection of three repeated spot urine samples for measurement of UIC, rather than relying on a single collection. This was an attempt to overcome the unacceptably large intra-individual variation associated with a single spot urine sample that may not provide a true picture of habitual iodine intake and underestimate low intakes in a deficient population (64). We have previously reported an association $(\mathrm{r}=0.230 ; \mathrm{P}<0.05)$ between urinary iodine concentrations and three repeated 24-hour dietary recalls (30), which indicates that UIC provides a valid indication of dietary iodine intake.

Other limitations include the cross-sectional study design which provides a snapshot of both cognitive function and iodine status of individuals at only one timepoint. The cross sectional analysis allows for hypothesis generation, but prospective studies are needed to identify a causal effect between long-term exposure to sub-optimal iodine intakes and subsequent cognitive dysfunction in old age. The study population is not representative of the general geriatric population as the convenience sample was recruited from one geographical are of regional New South Wales, Australia. Generalizability of the findings is thus limited.

The lack of an association between iodine status and cognitive function needs to be interpreted against the context of a relatively healthy, well educated population with mild iodine deficiency. Participants in the present study were all highly motivated volunteers, who were either independently living at home or were in low-level care residential facilities, and had a surprisingly good nutritional status. Different associations may be evident in populations with moderate and/or severe iodine deficiency and in those with altered thyroid function, as in those with evidence of malnutrition. In addition, thyroid hormone assessment, which is sensitive and specific, may provide a better indication of iodine status than urinary and dietary iodine values.

\section{Conclusion}

Iodine status was neither associated with cognitive performance nor mood state in a sample of healthy older Australians. Memory function was positively associated with nutritional status while negatively influenced by depressed mood. Future studies may include older participants with severe iodine deficiency or with hypothyroidism to further examine a possible relationship between iodine intake and cognitive function in older adults.

Ethical Standards: The study protocol was approved by the University of Wollongong Human Research Ethics Committee and all subjects provided written informed consent.

Conflicts of Interest: No authors have any conflicts of interest to declare

\section{References}

1. Vara H, Munoz-Cuevas J, Colino A. Age-dependent alterations of long-term synaptic plasticity in thyroid-deficient rats. Hippocampus 2003;13: 816-825

2. Zimmermann MB, Connolly K, Bozo M. Iodine supplementation improves cognition in iodine-deficient schoolchildren in Albania: a randomized, controlled, double-blind study. Am J Clin Nutr 2006;83: 108-114.

3. Bleichrodt N, Born MP. A meta analysis of research on iodine and its relationship to cognitive development. In: Stanbury JB (ed) The damaged brain of iodine deficiency cognitive, behavioral, neuromotor, educative aspects. Cognizant Communications Corporation, 1994;pp195-200

4. Canaris GJ, Manowitz NR, Mayor G et al. The Colorado Thyroid Disease Prevalence Study. Arch Intern Med 2000;160: 526-534.

5. D $\mu$ gbartey AT. Neurocognitive aspects of hypothyroidism. Arch Intern Med 2008;158: 1412-1428

6. Chueire VB, Silva ET, Perotta E et al. High serum TSH levels are associated with depression in the elderly. Arch Gerontol Geriatr 2003;36; 281-288

7. Cao, XI, Jiang, XM, Dou, ZH et al. Timing of Vulnerability of the Brain to Iodine Deficiency in Endemic Cretinism. The New England Journal of Medicine 1994;331: 1739-1744

8. Tiwari, BD, Godbole, MM, Chattopadhyay, $\mathrm{N}$ et al. Learning disability and poor motivation to achieve due to prolonged iodine deficiency. American Society for Clinical Nutrition 1996;63:782-786

9. Huda, SN, Grantham-McGregor, SM, Rahman, KM et al. Biochemical Hypothyroidism Secondary to Iodine Deficiency is associated with poor school achievement and cognition in Bangladeshi children. American Society for Nutritional Sciences 11999;29: 980-987.

10. Riggs, KM, Spiro A, Tucker, K et al. Relations of vitamin B-12, vitamin B-6, folate, and homocysteine to cognitive performance in the Normative Aging Study. American Society for Clinical Nutrition 1996;63: 306-314

11. Selhub, J, Bagley, LC, Miller, J et al. B vitamins, homocysteine, and neurocognitive function in the elderly. American Journal of Clinical Nutrition 2000;71(suppl): 614S-620S

12. Gonzalez-Gross, M, Marcos, A and Pietrzik. Nutrition and cognitive impairment in the elderly. British Journal of Nutrition 2001;86: 313-321

13. Manders, M, de Groot, LCPGM, van Staveren, WA et al. Effectiveness of Nutritional Supplements on Cognitive Functioning in Elderly Persons: A Systematic Review. Journal of Gerontology 2004;59A: 1041-1049

14. Li M, Ma G, Guttikonda K, Boyages SC, Eastman CJ. Re-emergence of iodine deficiency in Australia. Asia Pac J Clin Nutr 2001;10: 200-203

15. Guttikonda K, Travers CA, Lewis PR, Boyages S. Iodine deficiency in urban primary school children: a cross-sectional analysis. Med J Aust 2003;179:346348

16. McDonnell CM, Harris M, Zacharin MR. Iodine deficiency and goitre in schoolchildren in Melbourne, 2001. Med J Australia 2003;178: 159-162

17. Hamrosi MA, Wallace EM, Riley MD. Iodine status in pregnant women living in Melbourne differs by ethnic group. Asia Pac J of Clin Nutr 2005;14: 27-31

18. Travers CA, Guttikonda K, Norton CA et al. Iodine status in pregnant women and their newborns: are our babies at risk of iodine deficiency? Med J Australia 2006;184: 617-620

19. Seal JA, Doyle Z, Burgess JR et al. Iodine status of Tasmanians following voluntary fortification of bread with iodine. Med J Australia 2007;186: 69-71

20. Food Standard Australia New Zealand (FSANZ) (2008) 22nd Australian Total Diet Study http://www.foodstandards.gov.au/newsroom/ publications / 22ndaustraliantotaldietstudy. Accessed 10 March 2009

21. Rahman, A, Savige, GS, Deacon, NJ et al. Urinary iodine deficiency in 
Gippsland pregnant women: the failure of bread fortification? Medical Journal of Australia 2011;194:240-43

22. Clifton VL, Hody NA, Fogarty PA et al. The impact of iodine supplementation and bread fortification on urinary iodine concentrations in a mildly iodine deficient population of pregnant women in South Australia. Nutr J 2013;12: 32

23. Charlton $\mathrm{KE}$, Yeatman $\mathrm{H}$, Brock $\mathrm{E}$ et al. Improvement in iodine status of pregnant Australian women 3 years after introduction of a mandatory iodine fortification programme. Prev Med 2013;57: 26-30

24. Depaoli, KM, Seal, JA, Burgess, JR et al. Improved iodine status in Tasmanian schoolchildren after fortification of bread: a recipe for national success. Med J Aus 2013;198(9):492-4

25. Australian Bureau of Statistics (ABS). 3235.0 Population by Age and Sex, Regions of Australia, 2012 http: / / www.abs.gov.au/ausstats/abs@.nsf /

26. Deary, IJ, Corley, J, Gow, AJ et al (2009) Age-associated cognitive decline. Br Med Bull, 2009;92: 135-152

27. Miller, KJ, Parsons, TD, Whybrow, PC, et al. Memory improvement with treatment of hypothyroidism. Intern J Neuroscience, 2006;116: 895-906

28. Folstein, M, Folstein, F and McHugh, P. "Mini-Mental State". A practica method for Grading the Cognitive State of Patients for the Clinician. Journal of Psychiatric Research 1975;12: 189-198

29. Ohashi T, Yamaki M, Pandav C, Karmarkar M and Irie M. Simple microplate method for determination of urinary iodine. Clinical Chemistry 2000;46:529536

30. Tan, LM, Charlton KE, Tan, ZY, Ma, G, Batterham, M. Validity and reproducibility of an iodine-specific food frequency questionnaire to estimate dietary iodine intake in older Australians. Nutrition and Dietetics 2012;70: 71-78.

31. Guigoz Y, Vellas B, Garry P. Assessing the nutritional status of the older person: the Mini Nutritional Assessment as part of the geriatric evaluation. Nutr Rev 1996;54: S59-S65.

32. CogState Ltd. CogState Battery of Tests. Melbourne, Australia, 2009

33. Falleti, MG, Maruff, P, Collie, A and Darby, DG. Practice Effects Associated with the Repeated Assessment of Cognitive Function Using the CogState Battery at 10-minute, One Week and One Month Test-retest Intervals. Journal of Clinical and Experimental Neuropsychology. 2006;28: 1095-1112

34. Rey, A. Psychological examination of traumatic encephalopathy. Archieves de Psychologie 1941;28: 286-340.

35. Yesavage, J, Brink, T, Rose et al. Development and validation of a geriatric depression screening scale: A preliminary report. Journal of Psychiatric Research 1983;17: 37-49

36. Brink, T, Yesavage, J, Lum O et al. Screening tests for geriatric depression. Clinical Gerontologist 1982;1: 37-44

37. Kim HK, Lee SY, Lee JI et al. Usefulness of iodine/creatinine ratio from spoturine samples to evaluate the effectiveness of low-iodine diet preparation for radioiodine therapy. Clinical Endocrinology 2010;73: 114-118.

38. SPSS Version 15 for Windows (2006) SPSS Inc: Chicago, IL, USA.

39. Gunton JE, Hams G, Fiegert M, McElduff A. Iodine deficiency in ambulatory patients attending a Sydney teaching hospital: is Australia truly iodine replete? Med J Aust 1999;171:467-70.

40. Li M, Eastman CJ, Waite KV et al. Are Australian children iodine deficient? Results of the Australian National Iodine Nutrition Study. Med J Aust 2006;184:165-9

41. Huda, SN, Grantham-McGregor, SM and Tomkins, A. Cognitive and Motor Functions of Iodine-deficient but euthyroid children in Bangladesh do not benefit from iodized poppy seed oil (Lipiodol). American Society for Nutritional Sciences 2001;131: 72-77

42. Hashimoto K, Curty FH, Borges PPet al. An unliganded thyroid hormone receptor causes severe neurological dysfunction. PNAS 2001;98: 3998-4003.

43. Dong, J, Yin, H, Liu, W et al. Cogenital Iodine Deficiency and Hypothyroidism Impair LTP and Decress C-fos and C-jun Expression in Rat Hippocampus. NeuroToxicology 2005;26: 417-426

44. Calvo, R, Obregon, MJ, de Onha, CR et al. Congenital Hypothyroidism, as studied in rats: crucial role of maternal thyroxine but not of 3,5,3'Triiodothyronine in the protection of the fetal brain. The Journal of Clinical Investigation 1990;86: 889-899
45. Martínez-Galán JR, Pedraza P, Santacana M et al. Early effects of iodine deficiency on radial glial cells of the hippocampus of the rat fetus. A model of neurological cretinism. J Clin Invest 1997;99:2701-9

46. Bernal, J and Pekonen, F. Ontogenesis of the Nuclear 3,5,3'- Triiodothyronine receptor in the human fetal brain. Endocrinology 1983;114: 677-679

47. Ferreiro, B, Bernal, J, Goodyer, G et al.Estimation of Nuclear Thyroid Hormone Receptor Saturation in Human Fetal Brain and Lung During Early Gestation. J Clin Endocrinol Metab 1988;67: 853-856

48. Fernandez-Lamo, I, Montero-Pedrazuela, A, Delgado-Garcia, JM et al. Effects of thyroid hormone replacement on associative learning and hippocampal synaptic plasticity in adult hypothyroid rats. European Journal of Neuroscience 2009;30: 679-692

49. Cysique, LA, Maruff, $\mathrm{P}$ and Brew, BJ. The neuropsychological profile of symptomatic AIDS and ADC patients in the pre-HAART era: a metaanalysis. Journal of the International Neuropsychological Society 2006;12: 368-382

50. Lim, YY, Ellis KA, Harringto $\mathrm{K}$ et al. Cognitive decline in adults with mild cognitive impairment and high $\mathrm{A} \beta$ amyloid: prodromal Alzheimer's disease? Journal of Alzhiemer's Disease 2013; 33: 1167-1176

51. Cockle, SM, Haller J et al. The influence of multivitamins on cognitive function and mood in the elderly. Aging Ment Health 2000;4: 339-353

52. Harris, E, Macpherson, H, Vitetta, L et al. Effects of a multivitamin, mineral and herbal supplement on cognition and blood biomarkers in older men: a randomised, placebo-controlled trial. Hum Psychopharmacol. 2012;27: $370-$ 377

53. Macpherson, H, Pipingas, A, Pase, MP. Multivitamin-multimineral supplementation and mortality: a meta-analysis of randomized controlled trials. Am J Clin Nutr 2013;97: 437-444

54. Fredrickson, J et al. Evaluation of the usability of a brief cognitive screening test in older people for epidemiological studies. Neuroepidemiology 2010;34: $65-75$

55. Chandra RK. Effect of vitamin and trace-element supplementation on cognitive function in elderly subjects. Nutrition 2001;17: 709-712

56. Wouters-Wesseling W1, Wagenaar LW, Rozendaal M, Deijen JB. Effect of an enriched drink on cognitive function in frail elderly persons. J Gerontol A Biol Sci Med Sci 2005;60: 265-270

57. Feng, L, Li, J, Yap, K et al. Vitamin B-12, apolipoprotein E genotype, and cognitive performance in community-living older adults: evidence of a genemicronutrient interaction. American Journal of Clinical Nutrition 2009;89: 1263-1268

58. The NEMO Study Group. Effects of a 12-mo micronutrient intervention on learning and memory in well-nourised and marginally nourished schoolaged children: 2 parallel, randomised, placebo-controlled studies in Australia and Indonesia. American Journal of Clinical Nutrition 2007;86: 1082-1093

59. Bruner, AB, Joffe, A, Duggan, AK et al. Randomised study of cognitive effects of iron supplementation in non-anaemic iron deficient adolescent girls. Lancet 1996;348: 992-996

60. Bryan, J, Osendarp, S, Hughes, D et al. Nutrients for cognitive development in school-aged children. Nutr Rev 2004;62: 295-306

61. Burt, DB, Zembar, MJ, Niederehe, G. Depression and memory impairment: A meta-analysis of the association, its pattern, and specificity. Psych Bull 1995;117: 285-305

62. World Health Organization, United Children's Fund \& International Council for the Control of Iodine Deficiency Disorders. Assessment of iodine deficiency disorders and monitoring their elimination: a guide for programme managers. 3rd edition. Geneva: World Health Organization, 2007.

63. Ristic-Medic, D., Piskackova, Z., Hooper, L., Ruprich, J., Casgrain, A., Ashton,K., Pavlovic, M. and Glibetic, M. Methods of assessment of iodine status in humans: A systematic review. Am. J. Clin. Nutr. 2009;89:2052S-2069S

64. Mackerras DEM, Singh GR, Eastman CJ. Iodine status of Aboriginal teenagers in the Darwin region before mandatory iodine fortification of bread. Med J Austr 2011;194:126-130. 